Pollination of the European fooddeceptive Traunsteinera globosa (Orchidaceae)

The importance of nectar-producing neighbouring plants

\author{
Journal Article \\ Author(s): \\ Juillet, N.; Gonzalez, M.A.; Page, P.A.; Gigord, L.D.B. \\ Publication date: \\ 2007-05 \\ Permanent link: \\ https://doi.org/10.3929/ethz-b-000067653
}

Rights / license:

In Copyright - Non-Commercial Use Permitted

Originally published in:

Plant Systematics and Evolution 265(1-2), https://doi.org/10.1007/s00606-006-0507-9 
Pl. Syst. Evol. 265: 123-129 (2007)

Plant Systematics

DOI 10.1007/s00606-006-0507-9

and Evolution

Printed in The Netherlands

Short Communication

\title{
Pollination of the European food-deceptive Traunsteinera globosa (Orchidaceae): the importance of nectar-producing neighbouring plants
}

\author{
N. Juillet ${ }^{1}$, M. A. Gonzalez, P. A. Page ${ }^{3}$, and L. D. B. Gigord ${ }^{1}$ \\ ${ }^{1}$ Department of Ecology and Evolution, University of Lausanne, Lausanne, Switzerland \\ ${ }^{2}$ Laboratoire Evolution et Diversité Biologique, Université Paul Sabatier, Toulouse, France \\ ${ }^{3}$ Institut für Integrative Biologie, ETH Zurich, Zürich, Switzerland
}

Received June 9, 2006; accepted November 27, 2006

Published online: February 28, 2007

(c) Springer-Verlag 2007

\begin{abstract}
European food-deceptive orchids generally flower early in spring and rely on naïve pollinators for their reproduction. Some species however, flower later in the summer, when many other rewarding plants species are also in bloom. In dense flowering communities, deceptive orchids may suffer from competition for pollinator resources, or might alternatively benefit from higher community attractiveness. We investigated the pollination strategy of the deceptive species Traunsteinera globosa, and more specifically whether it benefited from the presence of coflowering rewarding species. We carried out a population survey to quantify the density and reproductive success of the orchid as well as the density of all coflowering species. Our results suggest that the deceptive orchid not only benefited from the presence of coflowering species, but that interestingly the density of the species Trifolium pratense was significantly positively correlated with the orchid's reproductive success. This species might simply act as a magnet species attracting pollinators near $T$. globosa, or could influence the orchid reproductive fitness through a more species-specific interac-
\end{abstract}

tion. We propose that morphological or colour similarities between the two species should be investigated in more detail to decipher this pollination facilitation effect.

Key words: Traunsteinera globosa, Pollination facilitation, Rewardless orchids, Density, Pollinators, Magnet species.

\section{Introduction}

In animal pollinated plants, indirect interaction between plant species can take place if they share a common pollinator resource (Waser and Real 1979, Callaway 1995). Competition for pollination occurs if pollinator sharing leads to a reduction in pollination success for at least one of the species in the community considered, and can happen for example, when reward is not equal among interacting species (Laverty 1992), or when interspecific pollen transfer occurs (Rathcke 1983), causing stigma 
clogging or pollen discounting (Campbell 1985). Alternatively, these interactions can be positive when a species increases its fitness by flowering close to one or several other blooming species. Pollination facilitation may occur through two main mechanisms (Moeller 2004). First, plants flowering simultaneously in a community may collectively attract more pollinator because of a larger general floral display (Moeller 2004) or a greater floral diversity (Fontaine et al. 2006, Ghazoul 2006). Second, the co-occurrence of several flowering plant species in a community can maintain pollinators for a longer time (Moeller 2004). However, relatively few studies have demonstrated pollination facilitation to date, and the fitness consequences of pollinator sharing between interacting species can seldom be predicted.

One specific situation where pollination facilitation is likely to be of high importance is when deceptive orchids are involved. These species do not provide a nectar or pollen reward to their pollinators (Dafni 1987), and mostly rely on the innate behaviour of foraging insects for their reproduction ("generalized food deception": Nilsson 1992, Jersáková et al. 2006). This deceit pollination strategy occurs in about one third of orchid species, and has received considerable attention for over a century (Sprengel 1793, Darwin 1862). Because insect pollinators can learn to discriminate between rewarding and rewardless species, and as a consequence to shortly avoid them, fooddeceptive orchids often have a lower reproductive success compared to their rewarding relatives (Neiland and Wilcock 1998). Deceptive orchid species should in general benefit from the proximity of rewarding species, by attracting and maintaining pollinator population in the community (the "magnet species effect": Thomson 1978). Moreover, it is expected that the reproductive success of a deceptive species in a natural community should be positively correlated with the density of rewarding magnet species (Ferdy et al. 1998, Johnson et al. 2003).

However, results are still puzzling and more studies to generalize about the impor- tance of coflowering species for deceptive orchids reproductive success are needed. For example, Johnson et al. (2003) found a positive relationship between the reproductive success of Orchis morio and the density of surrounding nectar producing species, indicating pollination facilitation, while Alexandersson and Ågren's (1996) study of Calypso bulbosa found this relationship in only one out of three years. Oppositely, Lammi and Kuitunen (1995) found a negative effect of experimentally added rewarding Viola $s p$. to natural stands of Dactylorhiza incarnata.

The present study is focused on Traunsteinera globosa, a rewardless orchid that flowers in Alpine meadows, synchronously with numerous rewarding plant species. Our aim is to test the impact of coflowering species on the orchid's reproductive success, and to see whether pollination facilitation occurs in natural populations. If so, we expect a positive relationship between coflowering species' density and orchid reproductive success (Johnson et al. 2003).

Similarly, we expect a negative relationship between deceptive orchid density and its reproductive success (Alexandersson and Ågren 1996) as a consequence of pollinator's learning ability to avoid deceptive species, or of a general decrease of the community profitability. We used a large population survey to explore these hypotheses.

\section{Materials and methods}

Study species. Traunsteinera globosa (L.) Reichenbach is a European terrestrial orchid, growing typically in Alpine meadows from mid-June to the end of July, from 1000 to $2500 \mathrm{~m}$ in altitude. Its general appearance is a long stem, varying from 15 to $80 \mathrm{~cm}$ (mean \pm SD: $35.6 \pm 8.4 \mathrm{~cm}, \mathrm{~N}=2087$ ), with a single globe-like inflorescence of up to 200 flowers (mean $\pm \mathrm{SD}$ : $51.6 \pm 19.6, \mathrm{~N}=2087$ ). Each flower is less than $1 \mathrm{~cm}$ long, with a short and nectarless spur, displaying light to bright pink petals often blurred with dark pink dots. Data on pollinators are very scarce; Vöth (1994) reported visits of Lepidoptera, Coleoptera, Diptera and Hymenoptera on $T$. globosa flowers, but with no 
mention of effective pollination. Dafni (1987) observed Syrphid flies on T. globosa. The fly Empis livida have been also observed to visit sequentially many $T$. globosa plants in a Swiss population but without noticeable pollinia removal from flowers (L.D.B. Gigord, personal observation).

Study sites. In the summer 2003, we studied 26 populations distributed across Western Switzerland. These populations were located in two mountain ranges, the Jura and the Alps, covering an area of 100 by $200 \mathrm{~km}$. In each population, we set up a rectangle of $50 \times 30 \mathrm{~m}$ in which we counted, mapped and measured inflorescence height of all flowering $T$. globosa individuals. In a randomly selected row of $5 \times 50 \mathrm{~m}$ within each rectangle, we counted all co-occurring flowers or inflorescences, depending on the species, to obtain estimates of coflowering species' densities. Approximately four weeks later, we recorded fruit set for each orchid plant (number of fruit produced divided by the total number of flowers) as a measure of reproductive success. This time lapse appeared to be sufficient to unambiguously detect any fruit formation. The ability for spontaneous autogamy was tested on six plants from three populations in 2002 and 12 plants from one population in 2003, by covering tested plants with a fine insect-proof netting bag during the entire flowering season.

Statistical analysis. In a first analysis, we tested if individual reproductive success was linked to flower number and inflorescence height, as observed in other orchid species (Nilsson 1980, Gumbert and Kunze 2001). As these two measures were highly correlated (correlation coefficient $=$ 0.63 , Pearson's $t=37.10, \mathrm{p}<0.001$ ), we retained inflorescence height for subsequent analysis as the more correlated to fruit set.

Second, we used a generalized linear model (GLM) to explore the relationship between $T$. globosa fruit set (response variable) and population altitude, T. globosa density, coflowering species density and species richness. We applied a backward stepwise model selection to obtain the final model, with significance of term and overall AIC as criterion for model selection.

In the 26 sampled populations, we recorded overall 104 species coflowering with T. globosa (mean per population $\pm \mathrm{SD}: 25.08 \pm 4.72$ ). For each species present in more than two populations, we estimated the relationship between its density and T. globosa reproductive success using regression analysis. When a regression was found to be significant, we added this species density as an explanatory variable in a new GLM to measure its significance. We used the same simplification method as above. We used the R 2.0.1 statistical software for all analyses (R Development Core Team 2004).

\section{Results}

Covered plants did not produce any fruit neither in 2002 nor in 2003, indicating a complete dependence on pollinators to achieve its reproduction. In the sampled populations, T. globosa individuals presented a high overall proportion of fruit set: $0.56 \pm 0.21$ (mean \pm $\mathrm{SD}, \mathrm{N}=2087$ ). The average number of fruits per plant, and thus the number of effective visits to individual flowers was high: $29.5 \pm$ 17.3 (mean $\pm \mathrm{SD}, \mathrm{N}=2087$ ). At the population level, mean fruit set was $0.53 \pm 0.11$ (mean $\pm \mathrm{SD}, \mathrm{N}=26$ ), and differed significantly among populations (Kruskal rank sum test, $\mathrm{W}=489.97, \mathrm{df}=25, \mathrm{p}<0.001)$. There was a significant $\left(\mathrm{F}_{1,2077}=83.6, \mathrm{p}<2 \times 10^{-16}\right)$ but faint $\left(\mathrm{r}^{2}=0.03\right)$ positive linear relationship between $T$. globosa fruit set and inflorescence height. To correct for this relationship, we used in the following analysis the populationaveraged residuals of the regression between orchid fruit set and inflorescence height as the response variable, instead of mean population fruit set.

Our GLM indicated that T. globosa fruit set was highly positively correlated with altitude and coflowering species density (Table 1a). The two other variables (namely $T$. globosa density and community richness) showed a positive yet not significant influence on $T$. globosa fruit set and were removed through model simplification.

In the linear regression analysis, both Geranium sylvaticum and Trifolium pratense densities had a significant effect on $T$. globosa reproductive success. Geranium sylvaticum, which was present in 14 populations, had a negative effect on $T$. globosa reproductive success (slope $=-0.516, \mathrm{~F}_{1,12}=7.0, \mathrm{p}=0.021$, 
Table 1. Results of the multiple regressions between $T$. globosa reproductive success and population variables. Variables included in initial models are indicated in $\mathbf{a}$ and $\mathbf{b}$ and are followed by the minimal adequate model after stepwise simplification

a Initial model:

Altitude + density of $T$. globosa + density of coflowering sp. + sp. richness

Null deviance $=0.349 ;$ AIC $=-54.065$

Simplified model:

Variable

Altitude

Density of coflowering species

df

$\%$ of total deviance

36.98

14.82

48.20

$\mathrm{AIC}=-49.255 ; \mathrm{r}^{2}=0.4762$

b Initial model:

Altitude + density of $T$. globosa + density of coflowering sp. (except $T$. pratense) + sp. richness + density of $T$. pratense

Null deviance $=0.349 ;$ AIC $=-57.401$

Simplified model:

Variable

Altitude

Density of $T$. pratense

$\%$ of total deviance

36.98

$23 \quad 19.28$
43.74

$\mathrm{p}$

Residuals

$<0.001$

0.014

$\mathrm{AIC}=-51.778 ; \mathrm{r}^{2}=0.5246$

$\left.\mathrm{r}^{2}=0.316\right)$. The density of $G$. sylvaticum was low (mean \pm SD: $0.073 \pm 0.128$ ) and represented only a small fraction of all the coflowering species (mean \pm SD: $1.065 \% \pm 3.041 \%$, median $=0.072 \%)$. Conversely, the density of $T$. pratense was positively linked to $T$. globosa reproductive success (slope $=0.03842, \mathrm{~F}_{1,24}=$ $\left.12.8, \mathrm{p}=0.0015, \mathrm{r}^{2}=0.321\right)$. Trifolium pratense occurred in all the populations in much higher density $(1.953 \pm 1.816$, median $=1.79)$ which represented $12.757 \% \pm 10.805 \%$ of all coflowering species (median = 9.810). Geranium sylvaticum density effect was not significant when included in a new GLM and was thus eliminated through model simplification. Oppositely, the effect of $T$. pratense density remained highly significant after GLM simplification (Table 1b).

\section{Discussion}

In this study, we show that $T$. globosa reproductive success is positively correlated with the density of nectar-producing coflower- ing species. This finding is in accordance with the magnet species hypothesis (Thompson 1978): the orchid benefits from greater pollinator abundance in the vicinity of nectar producing plants. This pollination facilitation pattern has been found in other deceptive species (Pellmyr 1986, Laverty 1992, Alexandersson and Ågren 1996, Johnson et al. 2003). Our study also showed that $T$. globosa reproductive success was positively correlated with altitude (Table 1a). This pattern might be due to a greater pollinator abundance or diversity in high altitude populations, although the opposite trend was more often described (Kalin Arroyo et al. 1982). It might also reflect hidden effects related to altitude such as, for instance, vegetation cover (wooded pastures vs. alpine meadows at low and high altitude respectively) or flowering time (mid-June to the end of July, Juillet et al., personal observations).

Contrarily to the prediction and other published studies (Alexandersson and Ågren 1996, Gumbert and Kunze 2001), our results 
showed no influence of $T$. globosa density on its own reproductive success. This may be explained by the unusual late flowering pattern for an European deceptive orchid (late June), at a time where flowering plant communities are very dense (15.26 \pm 7.12 coflowering plant. $\left.\mathrm{m}^{-2}\right)$ and diverse $(25.08 \pm 4.72$ species per quadrat) in Alpine meadows. Other studies that found such a detrimental effect of population density on reproductive success often reported results from orchid species that flower earlier in a relatively poor blooming background (Dafni 1983, Johnson et al. 2003). In our populations, the relative density of $T$. globosa compared to that of coflowering species was $5.2 \times 10^{-3} \pm 5.3 \times 10^{-3}$ (i.e. 5.2 orchid for 1000 flowers), which highly contrasts, for instance, with that of the food deceptive Dactylorhiza sambucina that flowers earlier in similar habitats (relative density: $1.02 \pm 1.55$ (similar density of orchid and coflowering species, Gigord et al., unpublished data).

Among all coflowering species, did any particular species have an influence on $T$. globosa reproductive success? It has been proposed that $T$. globosa is a mimic of the nectar producing species Scabiosa columbaria L. (Dipsacaceae), Knautia sylvatica L. (Dipsacaceae) and/or Valeriana montana L. (Valerianaceae) (Van der Cingel 1995 and references therein). This assumption was probably a result of the particular globular architecture of $T$. globosa inflorescences and the apparent corolla colour similarity among these four species (at least to human eyes), and was however never investigated. Our data suggest that this hypothesis is unlikely for several reasons. First, Knautia sylvatica was never found in our populations. Second, we found $S$. lucida instead of $S$. columbaria (very similar in floral morphology and colour) and it had a flowering peak after that of $T$. globosa. Third, $S$. lucida and $V$. montana were found in less than half of all the sampled populations. These distribution and phenological considerations did not fit with theoretical expectation regarding model and mimic co-occurrence. Finally, the density of these potential model species showed no relationship with $T$. globosa reproductive success, contrarily to what is expected in this type of mimicry systems (Roy and Widmer 1999).

Interestingly, Trifolium pratense density correlated positively with $T$. globosa reproductive success (Table $1 b$ ). This species was present at high density in the majority of populations, representing on average $13 \%$ of all coflowering species individuals. Also, this species is similar to T. globosa for inflorescence shape and, according to a bee colour-vision model (COC model, Vorobyev and Brandt 1997), both species are identical for corolla colour (Juillet et al. unpublished data), and this similarity should be extended to Hymenoptera and other insects with similar colour perceptions (Chittka et al. 1992). Trifolium pratense is mostly pollinated by Hymenoptera (bees and bumblebees) and Lepidoptera (personal observation), and either future direct observations of individual pollinator or indirect examination of interspecific pollen transfer (Rathcke 1983) would reveal if $T$. globosa and $T$. pratense actually share pollinator individuals.

Trifolium pratense can act as a magnet species that draws or maintains pollinator populations in the community, and T. globosa would then benefit in turn from their greater local abundance. However, it is possible that the corolla colour similarity with the orchid (if confirmed for insects other than bees) with the orchid is sufficient to confuse its pollinators, ensuring the reproduction of the deceptive orchid. This kind of non-specific mimicry effect has recently gained some support from both natural population (Orchis boryi, Gumbert and Kunze 2001) and experimental studies (Dactylorhiza sambucina, Gigord et al. 2002). Ultimately, $T$. pratense might be viewed as a potential new species-specific model for $T$. globosa. To test for a potential adaptive significance of the similarity between these two species, both manipulative experiments and behavioural tests (Johnson 2000, Anderson and Johnson 2006) should be performed. 
Could the observed relationship between $T$. pratense density and $T$. globosa reproductive success reflect facilitation other than for pollination? It can be proposed that $T$. pratense actually facilitates $T$. globosa (likewise other coflowering species) by increasing resource availability in the community through root-Rhizobium nitrogen fixation (Tate 2000). Such a facilitation for resource could explain the correlation found if setting fruit is resource-limited rather than pollination-limited, which is generally not the case in deceptive orchids (Neiland and Wilcock 1998, Tremblay et al. 2005). We propose thus that pollination facilitation is more likely to be the explanation for the observed relationship between $T$. globosa reproductive success and $T$. pratense density.

In a large-scale population survey, we showed that the density of all species that flower synchronously with $T$. globosa positively influenced the orchid's reproductive success. Because this orchid species relies on animal pollination to set seeds, a facilitative effect should reflect greater pollinator abundance in dense plant communities. Among these coflowering species, Trifolium pratense had the higher mean density and was present in all the studied populations. Moreover, its density showed a strong positive effect on $T$. globosa reproductive success, suggesting that this species might be a key explanation to the comparatively high pollination success of $T$. globosa. An interesting perspective will be to experimentally test by which mechanism(s) coflowering species, and particularly $T$. pratense, facilitates the pollination success of $T$. globosa.

The authors thank the "Arbeitsgruppe Einheimische Orchideen" (AGEO) for access to their orchid database, Agnès Hiou, Charlotte Trippi and all fieldwork assistants for their precious help. We thank Ann Smithson for constructive discussion about the studied species. We also thank Anne Atlan, Giorgina Bernasconi, Guillaume Besnard, Guillaume Evanno, Jaboury Ghazoul, Jana Jersáková, Giuseppe Pellegrino,
Amots Dafni and two anonymous reviewers for constructive comments on earlier versions of the manuscript. This research was supported by the Swiss National Science Foundation research grant referenced 3100A0-100754/1 to L. D. B. Gigord and the Department of Ecology and Evolution of the University of Lausanne.

\section{References}

Alexandersson R., Ågren J. (1996) Population size, pollinator visitation and fruit production in the deceptive orchid Calypso bulbosa. Oecologia 107: 533-540.

Anderson B., Johnson S. D. (2006) The effects of floral mimics and models on each other's fitness. Proc. Roy. Soc. B. 273: 969-974.

Callaway R. M. (1995) Positive interactions among plants. Bot. Rev. 61: 306-349.

Campbell D. R. (1985) Pollinator sharing and seed set of Stellaria pubella: competition for pollination. Ecology 66: 544-552.

Chittka L., Beier W., Hertl H., Steinmann E., Menzel R. (1992) Opponent colour coding is a universal strategy to evaluate the photoreceptor inputs in Hymenoptera. J. Comp. Physiol. A 170: 545-563.

Dafni A. (1983) Pollination of Orchis caspia - a nectarless plant species which deceives the pollinators of nectariferous species from other plant families. J. Ecol. 71: 464-474.

Dafni A. (1987) Pollination in Orchis and related genera: evolution from reward to deception. In: Arditti J. (ed.) Orchid biology: reviews and perspectives, Vol. 4. Cornell University Press, Ithaca, pp. 80-104.

Darwin C. (1862) On the various contrivances by which British and foreign orchids are fertilized by insects. John Murray, London.

Ferdy J.-B., Gouyon P.-H., Moret J., Godelle B. (1998) Pollinator behavior and deceptive pollination: learning process and floral evolution. Amer. Naturalist 152: 696-705.

Fontaine C., Dajoz I., Meriguet J., Loreau M. (2006) Functional diversity of plant-pollinator interaction webs enhances the persistence of plant communities. PLoS Biol. 4: 129-135.

Ghazoul J. (2006) Floral diversity and the facilitation of pollination. J. Ecol. 94: 295-304.

Gigord L. D. B., Macnair M. R., Stritesky M., Smithson A. (2002) The potential for floral 
mimicry in rewardless orchids: an experimental study. Proc. Roy. Soc. B. 269: 1389-1395.

Gumbert A., Kunze J. (2001) Colour similarity to rewarding model plants affects pollination in a food deceptive orchid, Orchis boryi. Biol. J. Linn. Soc. 72: 419-433.

Jersáková J., Johnson S. D., Kindlmann P. (2006) Mechanisms and evolution of deceptive pollination in orchids. Biol. Rev. 81: 219-235.

Johnson S. D. (2000) Batesian mimicry in the nonrewarding orchid Disa pulchra, and its consequences for pollinator behaviour. Biol. J. Linn. Soc. 71: 119-132.

Johnson S. D., Peter C. I., Nilsson L. A., Ågren J. (2003) Pollination success in a deceptive orchid is enhanced by co-occurring rewarding magnet plants. Ecology 84: 2919-2927.

Kalin Arroyo M. T., Primack R., Armesto J. (1982) Community studies in pollination ecology in the high temperate Andes of central Chile. I. Pollination mechanisms and altitudinal variation. Amer. J. Bot. 69: 82-97.

Lammi A., Kuitunen M. (1995) Deceptive pollination of Dactylorhiza incarnata: an experimental test of the magnet species hypothesis. Oecologia 101: 500-503.

Laverty T. M. (1992) Plant interactions for pollinator visits: a test of the magnet species effect. Oecologia 89: 502-508.

Moeller D. A. (2004) Facilitative interactions among plants via shared pollinators. Ecology 85: 3289-3301.

Neiland M. R. M., Wilcock C. C. (1998) Fruit set, nectar reward, and rarity in the Orchidaceae. Amer. J. Bot. 85: 1657-1671.

Nilsson L. A. (1980) The pollination ecology of Dactylorhiza sambucina (Orchidaceae). Bot. Notiser 133: 367-385.

Nilsson L. A. (1992) Orchid pollination biology. Trends Ecol. Evol. 7: 255-259.

Pellmyr O. (1986) The pollination ecology of two nectarless Cimifuga sp. (Ranunculaceae) in North America. Nordic J. Bot. 6: 713-723.

R Development Core Team (2004) R: A language and environment for statistical computing. R Foundation for Statistical Computing, Vienna, Austria. ISBN 3-900051-00-3. URL http:// www.R-project.org.
Rathcke B. (1983) Competition and facilitation among plants for pollination. In: Real L. (ed.) Pollination biology. Academic Press, New York, pp. 309-329.

Roy B. A., Widmer A. (1999) Floral mimicry: a fascinating yet poorly understood phenomenon. Trends Pl. Sci. 4: 325-330.

Sprengel C. K. (1793) Das Entdeckte Geheimniss der Natur im Bau und in der Befruchtung der Blumen (Reprinted in 1972). Weldon \& Wesley, New York.

Tate R. L. (2000) Soil microbiology. 2nd ed. John Wiley \& Sons, New York, pp. 374-395.

Thomson J. D. (1978) Effect of stand composition on insect visitation in two-species mixtures of Hieracium. Amer. Midl. Naturalist 100: 431-440.

Tremblay R. L., Ackerman J. D., Zimmerman J. K., Calvo R. N. (2005) Variation in sexual reproduction in orcids: a spasmodic journey to diversification. Biol. J. Linn. Soc. 84: 1-54.

van der Cingel N. A. (1995) An atlas of orchid pollination: European Orchids. AA Balkema, Rotterdam, The Netherlands.

Vorobyev M., Brandt R. (1997) How do insect pollinators discriminate colors? Israel J. Pl. Sci. 45: 103-113.

Vöth W. (1994) Bestäuber und Besucher der Blüten von Traunsteinera globosa (L.) Orchidaceae in Niederösterreich. Linzer Biologische Beiträge 26: 248-251.

Waser N. M., Real L. (1979) Effective mutualism between sequentially flowering plant species. Nature 281: 670-672.

Addresses of the authors: Nicolas Juillet (e-mail: Nicolas.Juillet@unil.ch), and Luc D. B. Gigord Department of Ecology and Evolution, Biophore Building, University of Lausanne, 1015 Lausanne, Switzerland. Mailyn A. Gonzalez, Laboratoire Evolution et Diversité Biologique UMR5174 CNRS - Université Paul Sabatier, 118 route de Narbone, 31062 Toulouse, France. Paul A. Page, Institut für Integrative Biologie, ETH Zurich, CHN G 31.1, Universitätstrasse 16, 8092 Zürich, Switzerland. 